\title{
Atendimento educacional especializado no contexto do Colégio de Aplicação da Universidade Federal do Rio Grande do Sul: de políticas a práticas
}

\author{
Mayara Costa da Silva ${ }^{1}$ \\ Carla Maciel da Silva ${ }^{2}$ \\ Tásia Fernanda Wisch ${ }^{3}$
}

\begin{abstract}
Resumo:
O presente estudo articula-se, metodologicamente, à abordagem qualitativa e tem como objetivo prioritário a constituição de uma cartografia acerca das políticas e práticas que se articulam ao atendimento educacional especializado no contexto específico do Colégio de Aplicação da Universidade Federal do Rio Grande do Sul. Partimos da seguinte questão orientadora: de que forma se desenha a estrutura do atendimento educacional especializado no âmbito do Colégio de Aplicação? Para tanto, nós nos pautaremos na análise documental de registros organizados pela área de educação especial da escola e das normativas que se associam à área no contexto brasileiro. A análise se constituiu a partir do referencial teórico que se associa ao pensamento sistêmico, sobretudo em Humberto Maturana e Francisco Varela, bem como em Gregory Bateson. Diante disso, torna-se possível perceber que o atendimento educacional especializado proposto, no contexto analisado, estrutura-se a partir do conceito de complexidade. Partindo das pistas indicadas pelos estudantes, valoriza-se e compõe-se um trabalho pautado na composição de uma rede de relações, na compreensão do diálogo como orientador do percurso e no compartilhamento de ações. Compreende-se, portanto, que se delineia, de forma prioritária, um processo de escolarização pensado a partir das relações entre seus partícipes.
\end{abstract}

\section{Palavras-chave:}

Educação especial. Atendimento educacional especializado. Inclusão escolar.

\footnotetext{
1 Doutora em Educação pelo Programa de Pós-Graduação em Educação da Universidade Federal do Rio Grande do Sul (UFRGS), Professora de Educação Especial no Colégio de Aplicação (UFRGS), Porto Alegre, RS, Brasil. E-mail: mayacsilva@gmail.com. ORCID iD: https://orcid.org/0000-0001-8716-0768.

2 Doutoranda em Educação pelo Programa de Pós-Graduação em Educação da Universidade Federal do Rio Grande do Sul (UFRGS), Professora de Educação Especial no Colégio de Aplicação (UFRGS), Porto Alegre, RS, Brasil. E-mail: carlamacieldasilva@ gmail.com. ORCID iD: https://orcid.org/0000-0002-7685-645X.

3 Doutora em Educação pelo Programa de Pós-Graduação em Educação da Universidade Federal de Santa Maria (UFSM), Professora de Educação Especial no Colégio de Aplicação (UFRGS), Porto Alegre, RS, Brasil. E-mail: tasiafw@gmail.com. ORCID iD: https://orcid.org/0000-0002-0356-6347.
} 


\title{
Specialized educational assistance in the context in the Colégio de Aplicação of the Universidade Federal do Rio Grande do Sul: from policies to practices
}

\begin{abstract}
:
The present study methodologically articulates the qualitative approach and has as a priority objective the constitution of a cartography about the policies and practices that are articulated to the specialized educational assistance in the specific context in the Colégio de Aplicação of the Universidade Federal do Rio Grande do Sul. We start from the following guiding question: How is the structure of specialized educational assistance designed within the scope of the Colégio de Aplicação? For this purpose, we will be guided by the documentary analysis of records organized by the special education area of the school and the regulations that are associated with the area in the Brazilian context. The analysis was based on the theoretical framework that is associated with systemic thinking, in a priority way, in Humberto Maturana and Francisco Varela, as well as in Gregory Bateson. Given this, it becomes possible to realize that the specialized educational assistance proposed, in the context analyzed, is structured based on the concept of complexity. Starting from the clues indicated by the students, a work based on the composition of a network of relationships, on the understanding of dialogue as a guide for the journey and on the sharing of actions is valued and composed. It is understood, in this way, that a process of schooling is outlined as a priority, based on the relationships between its participants.
\end{abstract}

Keywords:

Special education. Specialized educational assistance. School inclusion.

\section{Atención educacional especializada en el contexto del Colégio de Aplicação de la Universidade Federal do Rio Grande do Sul: de políti- cas a prácticas}

\section{Resumen:}

El presente estudio se articula, metodológicamente, al abordaje cualitativo y tiene como objetivo prioritario la constitución de una cartografía acerca de las políticas y prácticas implicadas en la atención educacional especializada en el contexto específico del Colégio de Aplicação de la Universidade Federal do Rio Grande do Sul. Partimos de la siguiente cuestión orientadora: ¿De qué manera se diseña la estructura de la atención educacional especializada en el ámbito del Colégio de Aplicação? Para eso, nos basamos en el análisis documental de registros organizados por el área de educación especial de la escuela y de las normativas que a esa área se asocian en el contexto brasileño. El análisis se constituyó a partir del referencial teórico que se vincula al pensamiento sistémico, de forma prioritaria, en Humberto Maturana y Francisco Varela, así como en Gregory Bateson. Ante eso, se vuelve posible percibir que la atención educacional especializada propuesta, en el contexto analizado, se estructura desde el concepto de complejidad. A partir de las pistas indicadas por los estudiantes, se valoriza y se compone un trabajo pautado en la composición de una red de relaciones, en la comprensión del diálogo como orientador del recorrido y en el intercambio de acciones. Se comprende, de esta manera, que se delinea, de forma prioritaria, un proceso de escolarización pensado a partir de las relaciones entre sus partícipes.

\section{Palabras clave:}

Educación especial. Atención educacional especializada. Inclusión escolar. 


\section{Introdução}

O atendimento educacional especializado pode ser lido como o serviço que assume centralidade em relação à política de educação especial na perspectiva da educação inclusiva, sendo elencada sua oferta como um dos objetivos principais da mesma e das normativas que a ela se associam no contexto brasileiro. (BRASIL, 2008; BRASIL, 2009; BRASIL, 2011). Ao olharmos para diferentes redes de ensino, tanto públicas como privadas, podemos afirmar que o formato desse atendimento vem se delineando com base nos contextos específicos em que se inserem, assumindo, assim, diferentes desenhos.

Nessa direção, os colégios de aplicação, inseridos no contexto brasileiro como instituições ligadas à rede federal de ensino, representam outro elemento de heterogeneidade frente às outras redes: por se constituírem como unidades específicas, ligadas às universidades federais em que se inserem, possuem autonomia para constituírem e organizarem os serviços ofertados, dentre eles, $o$ atendimento educacional especializado.

Diante disso, o presente texto tem como objetivo prioritário constituir uma cartografia acerca das políticas e práticas que se articulam ao atendimento educacional especializado no contexto específico do Colégio de Aplicação da Universidade Federal do Rio Grande do Sul (CAp/ UFRGS). A proposição parte da seguinte questão orientadora: de que forma se desenha a estrutura do atendimento educacional especializado no âmbito dessa instituição?

Para o desenvolvimento do estudo, nós nos pautaremos por uma abordagem metodológica relacionada à cartografia e optaremos pelo recurso metodológico da análise documental. A opção pela cartografia envolve a compreensão das articulações que ela apresenta com o referencial teórico associado ao pensamento sistêmico e sua priorização da "dimensão processual da realidade". (KASTRUP; PASSOS, 2013, p. 265).

Ao compreendermos a dimensão processual dos contextos de escolarização e do trabalho pedagógico desenvolvido no atendimento educacional especializado, evocamos o conceito de instabilidade, abordado por Vasconcellos (2013, p. 101), que nos sinaliza que "[...] o mundo está em processo de tornar-se". Desse modo, indicamos que, a partir da constituição de uma rede valorizadora do diálogo, caminhos e possibilidades vêm sendo instituídos durante o processo de constituição do trabalho desenvolvido no contexto em destaque.

A análise estrutura-se nos registros e documentos mantidos pela área de educação especial da instituição, bem como nas normativas brasileiras que tratam desse contexto. Por fim, apresentamos elementos específicos que se associam ao conceito de atendimento educacional especializado e às políticas e práticas que são produzidas por meio desse serviço, constituindo um desenho acerca do que vem sendo priorizado na estrutura e organização do serviço escolar.

\section{O atendimento educacional especializado nas normativas brasileiras}

Podemos afirmar que os últimos vinte anos têm expressiva importância na constituição da perspectiva inclusiva no que se refere à escolarização de estudantes com deficiência na escola regular. Diante disso, consideramos importante ressaltar alguns dos documentos normativos que se relacionam à área, com foco em um período que vai dos anos 2000 até os dias atuais.

A Resolução CNE/CEB nº 2, de onze de setembro de 2001, institui diretrizes nacionais para a educação especial na educação básica. Apesar de citar o atendimento educacional especializado, o documento não aprofunda o conceito acerca do que envolve o serviço. Sobre educação especial, segundo o documento, entende-se: 
[...] modalidade da educação escolar, entende-se um processo educacional definido por uma proposta pedagógica que assegure recursos e serviços educacionais especiais, organizados institucionalmente para apoiar, complementar, suplementar e, em alguns casos, substituir os serviços educacionais comuns, de modo a garantir a educação escolar e promover o desenvolvimento das potencialidades dos educandos que apresentam necessidades educacionais especiais, em todas as etapas e modalidades da educação básica. (BRASIL, 2001, p. 1, grifos nossos).

A Resolução, apesar de citar os recursos e serviços relacionados à área, indica, ainda, a possibilidade de o atendimento educacional especializado constituir-se de forma substitutiva à escolarização dos estudantes. Tal aspecto pode ser apontado como uma fragilidade do documento, pois abre a possibilidade de o atendimento desses sujeitos ocorrer em instituições especializadas, de forma substitutiva, como afirmam Mendes e Tosta (2012).

No ano de 2008, institui-se a Política Nacional de Educação Especial ${ }^{4}$ na perspectiva inclusiva, documento que altera o direcionamento político para a área, afirmando o direito dos estudantes público-alvo da educação especial ao acesso à escola regular. O objetivo desse documento é o de:

[...] assegurar a inclusão escolar de alunos com deficiência, transtornos globais do desenvolvimento e altas habilidades/superdotação, orientando os sistemas de ensino para garantir: acesso ao ensino regular, com participação, aprendizagem e continuidade nos níveis mais elevados do ensino; transversalidade da modalidade de educação especial desde a educação infantil até a educação superior; oferta do atendimento educacional especializado; formação de professores para o atendimento educacional especializado e demais profissionais da educação para a inclusão; participação da família e da comunidade; acessibilidade arquitetônica, nos transportes, nos mobiliários, nas comunicações e informação; e articulação intersetorial na implementação das políticas públicas. (BRASIL, 2008, p. 14).

Dessa forma, ao prever a escolarização desses estudantes na escola regular, sinaliza a transversalidade da educação especial a todos os níveis, etapas e modalidades de ensino, bem como prevê a garantia do atendimento educacional especializado de forma complementar ou suplementar à escolarização, ou seja, o atendimento não se organizará de forma substitutiva ao ensino comum, como podia ocorrer até então. A política conceitua o atendimento, em suas diretrizes, da seguinte forma:

O atendimento educacional especializado identifica, elabora e organiza recursos pedagógicos e de acessibilidade que eliminem as barreiras para a plena participação dos alunos, considerando as suas necessidades específicas. As atividades desenvolvidas no atendimento educacional especializado diferenciam-se daquelas realizadas na sala de aula comum, não sendo substitutivas à escolarização. Esse atendimento complementa e/ou suplementa a formação dos alunos com vistas à autonomia e independência na escola e fora dela [...] disponibiliza programas de enriquecimento curricular, o ensino de linguagens e códigos específicos de comunicação e sinalização, ajudas técnicas e tecnologia assistiva, dentre outros. Ao longo de todo processo de escolarização, esse atendimento deve estar articulado com a proposta pedagógica do ensino comum. (BRASIL, 2008, p. 16).

Torna-se possível afirmar a importância que a política assume como movimento orientador, tendo em vista que deixa claro, ao longo de seu texto, que as atividades que ocorrem no âmbito do atendimento educacional especializado diferenciam-se daquelas desenvolvidas na sala de aula regular, ou seja, não são substitutivas tampouco consideradas reforço escolar. $\mathrm{O}$ atendimento

4 No âmbito da política, passam a ser identificados como estudantes público-alvo da educação especial sujeitos com deficiências, transtornos globais do desenvolvimento e altas habilidades/superdotação. 
pode ser compreendido, portanto, como um serviço de apoio que, entre outras questões, constrói estratégias para a participação e aprendizagem do aluno no âmbito da sala de aula.

A Resolução CNE/CEB no 4, de dois de outubro de 2009, que “[...] institui diretrizes operacionais para o atendimento educacional especializado na educação básica, modalidade educação especial [...]", reafirma, em seu artigo $2^{\circ}$, a função complementar e suplementar do atendimento "[...] por meio da disponibilização de serviços, recursos de acessibilidade e estratégias que eliminem as barreiras para sua plena participação na sociedade e desenvolvimento de sua aprendizagem". (BRASIL, 2009, p. 1). Acerca do espaço de realização do atendimento, afirma:

O AEE é realizado, prioritariamente, na sala de recursos multifuncionais da própria escola ou em outra escola de ensino regular, no turno inverso da escolarização, não sendo substitutivo às classes comuns, podendo ser realizado, também, em centro de Atendimento Educacional Especializado da rede pública ou de instituições comunitárias, confessionais ou filantrópicas sem fins lucrativos, conveniadas com a Secretaria de Educação ou órgão equivalente dos Estados, Distrito Federal ou dos Municípios. (BRASIL, 2009, artigo 5º, p. 2).

As salas de recursos multifuncionais tornaram-se espaço de destaque com relação ao atendimento dos alunos público-alvo da educação especial. Baptista (2011), ao discutir a associação desse espaço, de forma prioritária, à atuação do professor de educação especial, questiona o termo "multifuncional" quando relacionado ao espaço em questão. O autor destaca a necessidade de revermos a ideia de multifuncional, que, neste caso, parece se associar às diferentes deficiências, indicando:

[...] penso que exista uma outra dimensão evocada com o termo multifuncional que merece ser abordada em nossos questionamentos. Multifuncional porque pode favorecer ou instituir uma pluralidade de ações que variam desde o atendimento direto ao aluno, ou a grupos de alunos, até uma ação em rede. Refiro-me ao acompanhamento de processos que ocorrem nas salas de aula comum, na organização de espaços transversais às turmas, em projetos específicos, na assessoria a colegas docentes, em contatos com familiares ou outros profissionais que têm trabalhado com os alunos. Para fazermos essa leitura da dimensão multifuncional, devemos deslocar nosso olhar da sala de recursos como um espaço físico e vislumbrá-lo como um espaço institucional necessariamente respaldado em um profissional que o representa: $o$ educador especializado. (BAPTISTA, 2011, p. 70).

Fazemos eco às palavras do autor, compreendendo a necessidade de pensarmos o atendimento educacional especializado para além de um espaço específico, tendo em vista a vida que pulsa na escola e a multiplicidade de espaços e movimentos que nela se apresentam. Diante disso, acreditamos na relevância de qualificarmos a compreensão do conceito de atendimento educacional especializado, assumindo-o como um serviço que se constitui em rede e que pode se deslocar para além de ideias fechadas que o articulam apenas aos espaços da sala de recursos, do atendimento individualizado, etc.

Outro aspecto a ser ressaltado refere-se ao fazer docente associado ao atendimento educacional especializado, o que é evocado na Resolução no 04/2009, ao citar, em seu artigo treze, as atribuições do professor de educação especial. Dentre as funções assumidas pelo profissional, oferecemos destaque ao planejamento de estratégias a partir das necessidades observadas em cada sujeito. Diante dessa função, compreendemos a multiplicidade de possibilidades que se abrem, no sentido de explorar o atendimento educacional especializado para além de um espaço específico.

Terão todos os estudantes as mesmas demandas com relação à utilização de um mesmo espaço, de um mesmo atendimento sempre individualizado? Sabemos que não. Dentre as funções assumidas por qualquer professor (não apenas o da educação especial), está a necessidade de se realizar a leitura das especificidades do estudante, sublinhando que os processos de construção 
de conhecimento se dão em diferentes tempos e que, portanto, requerem diferentes estratégias e proposições.

O Decreto $n^{\circ}$ 7.611, de dezessete de novembro de 2011, que "[...] dispõe sobre a educação especial, o atendimento educacional especializado e dá outras providências [...]", apresenta o atendimento educacional especializado como "[...] o conjunto de atividades, recursos de acessibilidade e pedagógicos organizados institucional e continuamente [...]”, a ser ofertado de forma complementar ou suplementar, conforme destacado em documentos anteriores. Indica, ainda, em seu artigo $3^{\circ}$, os objetivos do atendimento:

I - prover condições de acesso, participação e aprendizagem no ensino regular e garantir serviços de apoio especializados de acordo com as necessidades individuais dos estudantes;

II - garantir a transversalidade das ações da educação especial no ensino regular;

III - fomentar o desenvolvimento de recursos didáticos e pedagógicos que eliminem as barreiras no processo de ensino e aprendizagem; e

IV - assegurar condições para a continuidade de estudos nos demais níveis, etapas e modalidades de ensino. (BRASIL, 2011).

No ano de 2015, a Lei Brasileira de Inclusão reafirmou, em seu capítulo IV, o direito à educação por meio de um sistema educacional inclusivo. Apesar de destacar o direito ao atendimento educacional especializado, o documento não traz nenhum aprofundamento acerca do conceito. Afirma, no entanto, em seu artigo 28, que:

Incumbe ao poder público assegurar, criar, desenvolver, implementar, incentivar, acompanhar e avaliar [...] III - projeto pedagógico que institucionalize o atendimento educacional especializado, assim como os demais serviços e adaptações razoáveis, para atender às características dos estudantes com deficiência e garantir o seu pleno acesso ao currículo em condições de igualdade, promovendo a conquista e o exercício de sua autonomia. (BRASIL, 2015).

Corroboramos a importância e imprescindibilidade de um projeto pedagógico que institucionalize o atendimento educacional especializado, pois consiste em uma forma de garantir um direito, o qual estará anunciado tanto nas normativas quanto nos documentos internos da instituição, explicitando, ainda, a visibilidade dessa oferta.

A partir da leitura acerca das normativas brasileiras na área da educação especial sobre o atendimento educacional especializado, torna-se possível perceber que há uma vinculação direta à sala de recursos multifuncional ou a um conjunto de estratégias técnicas específicas. Nesse sentido, percebe-se a emergência de olharmos para a composição do atendimento.

Na mesma medida, percebemos um movimento importante, que aparece em quase todos os documentos analisados, destacando a observação das necessidades de cada sujeito para, então, se realizar o planejamento de estratégias específicas de atendimento. Esse movimento nos oferece uma pista acerca da compreensão de um atendimento que não se apresenta dentro de um modelo único, mas que precisa ser construído tomando como base as especificidades de cada um dos estudantes a ser atendido. Aqui, quando falamos em necessidades ou especificidades, não estamos evocando as tipologias de deficiência, mas sim a dimensão de subjetividade que se associa a cada um desses sujeitos e que precisa ser levada em consideração no âmbito da ação docente.

Diante disso, na medida em que essa possibilidade se articula a uma leitura de elementos presentes nas normativas, os quais se relacionam, de forma direta, à ação do docente responsável pelo atendimento educacional especializado, apontamos para a potência e para a ressignificação da ação que se relaciona, também diretamente, ao trabalho do professor, na busca por valorizar a dimensão da criação associada ao trabalho deste. 


\section{O Colégio de Aplicação da UFRGS (CAp/UFRGS)}

O Cap/UFRGS foi fundado no ano de 1954, pautado no Decreto Lei no $9.043 / 1946$. O projeto de criação dos colégios de aplicação se constitui a partir da necessidade da criação de escolas laboratórios. Essa iniciativa buscava estruturar espaços que servissem como campo para estágios e práticas de disciplinas didáticas dos cursos de licenciatura. Inicialmente, as atividades aconteciam junto à Faculdade de Filosofia, por meio da oferta do curso denominado de Ginásio. ${ }^{5}$

A ampliação de oferta de turmas foi acontecendo gradativamente ao longo dos anos seguintes. Em 1971, o Colégio passou a se vincular à Faculdade de Educação e se mudou para as dependências do prédio. No ano de 1985, o CAp/UFRGS passou a oferecer $1^{\circ} \mathrm{e} 2^{\circ}$ graus completos. A mudança física para o Campus do Vale, no bairro Agronomia, aconteceu no ano de 1996.

Cabe destacar que, inicialmente, o ingresso ocorreu absorvendo os alunos excedentes das seleções dos colégios porto-alegrenses: Instituto de Educação e Júlio de Castilhos. Na sequência, a instituição passou a realizar testes de seleção, sendo que, somente nos anos 1980, foi adotado o ingresso por meio de sorteio público, o qual está em vigência atualmente. A partir disso, pode-se afirmar que os estudantes que frequentaram e frequentam a instituição ingressaram a partir da ampla concorrência, o que justifica a diversidade do público atendido, bem como um número pouco expressivo de matrículas de estudantes com deficiências, autismo ou altas habilidades/superdotação.

Atualmente, o CAp/UFRGS ${ }^{6}$ constitui-se como uma instituição de educação básica, oferecendo turmas desde o primeiro ano do ensino fundamental até o terceiro ano do ensino médio do ensino regular e turmas de nível fundamental e médio na modalidade de Educação de Jovens e Adultos (EJA).

O órgão deliberativo da instituição é o conselho de unidade (CONSUNI), composto por representações de todos os segmentos: direção, vice-direção, chefes de departamento, gerente administrativa, bibliotecária-chefe, coordenadora da Comissão de Ensino (COMEN), coordenador da Comissão de Pesquisa (COMPESQ), coordenadora da Comissão de Extensão (COMEX), representante docente, representante dos técnicos administrativos, representante discente e representante da Comunidade de Pais e Mestres (COPAME).

A estrutura da instituição é organizada pela direção e vice-direção, pela gerência administrativa, pelos núcleos da unidade e pelas comissões permanentes.

A gerência administrativa tem a função de coordenar os serviços técnicos e administrativos e possui, vinculados a ela, os seguintes setores: Setor de Atendimento Escolar (SAE), Setor de Infraestrutura, Setor Financeiro, Secretaria Administrativa, Setor Técnico Especializado e Fonoaudiologia Escolar. Além disso, a instituição conta com serviço de enfermagem.

Os núcleos da unidade são os seguintes: Núcleo de Apoio ao Ensino (NAE), que é responsável pelo apoio técnico às atividades de ensino; Núcleo de Orientação e Psicologia (NOPE), o qual conta com serviços multidisciplinares de orientação educacional, de psicologia escolar e de serviço social; e Núcleo Setorial de Informática (NSI), que é formado por duas professoras da área de informática e bolsistas, prestando serviços relacionados à área da informática.

Além de comissões transitórias que são estruturadas conforme demanda, o CAp/UFRGS possui três comissões permanentes: Comissão de Pesquisa (COMPESQ), que, em articulação com a Pró-Reitoria de Pesquisa, avalia e acompanha a execução de pesquisas na instituição; Comissão de Extensão (COMEX), que, em articulação com a Pró-Reitoria de Extensão, avalia e acompanha

\footnotetext{
$5 \mathrm{O}$ ginásio referia aos quatro anos seguintes à escola primária. No contexto atual, trata-se dos anos finais do Ensino Fundamental. Disponível em: <http://www.dominiopublico.gov.br/download/texto/me002202. pdf >. Acesso em: 22 out. 2020.

6 Todas as informações apresentadas no título três, referentes à apresentação do Colégio de Aplicação, são decorrentes da tese de Wisch (2020), que se encontra em processo de publicação.
} 
projetos e programas de extensão; e Comissão de Ensino (COMEN), que consiste no principal espaço voltado às discussões de caráter pedagógico da instituição, não tendo poder deliberativo, ou seja, trata-se de um órgão consultivo.

Os professores são divididos em quatro departamentos, os quais contemplam as seguintes áreas do conhecimento:

1. Departamento de Humanidades (DHUM): anos iniciais, educação especial, geografia, história, filosofia e sociologia;

2. Departamento de Comunicação (DEPCOM): língua portuguesa e literatura, alemão, inglês, espanhol e francês;

3. Departamento de Expressão e Movimento (DEM): educação física, artes visuais, teatro, dança e música;

4. Departamento de Ciências Exatas e da Natureza (DCEN): física, matemática, biologia, química, informática e educação especial?

Nos aspectos pedagógicos, o CAp/UFRGS organiza-se a partir de projetos de ensino, que, neste momento, são cinco:

5. Projeto Unialfas: atende os anos iniciais do ensino fundamental. As aulas acontecem no período matutino.

6. Projeto Amora: atende turmas de sexto e sétimo ano. Possui sete turnos semanais.

7. Projeto Pixel: contempla os dois últimos anos do ensino fundamental (oitavo e nono anos). Possui sete turnos semanais.

8. Projeto Ensino Médio: contempla o ensino médio como um todo. Possui sete turnos semanais.

9. Projeto EJA: contempla turmas de alfabetização e de ensino fundamental e médio da Educação de Jovens e Adultos. Possui cinco turnos semanais e se dá no turno noturno.

No que se refere à área da educação especial, essa se organiza conforme pressupostos legais, transversalizando todos os projetos de ensino, segundo as matrículas dos estudantes público-alvo da educação especial.

\section{O atendimento educacional especializado no contexto do CAp/UFRGS}

A área de educação especial do Colégio de Aplicação da UFRGS passa a se constituir no ano de 2015, quando chega à instituição, por meio de uma redistribuição, a primeira professora de educação especial. Naquele momento, apesar de a instituição já contar com a presença de alunos com deficiência, não havia a oferta de atendimento educacional especializado.

Com a chegada dessa professora, passa a se organizar uma proposição de atendimento, mesmo que ainda muito restrito, tendo em vista que uma única docente atendia toda a escola, composta, naquele momento, por 677 alunos $^{8}$ ao total. Cabe destacar que, no ano de 2020, a escola conta com um total de 588 alunos, sendo vinte alunos público-alvo da educação especial ${ }^{9}$.

A chegada da segunda e da terceira professoras de educação especial ocorre nos anos de 2018 e de 2020, respectivamente, a partir de um concurso público. As docentes passam, então, a se dividir por equipes, o que qualifica o atendimento de todas as demandas da área, bem como a participação em todas as reuniões, discussões sobre alunos, etc.

\footnotetext{
7 A área de educação especial do CAp/UFRGS, até o ano de 2021, era composta por três professoras efetivas lotadas em departamentos diferentes.

8 Dados levantados pelas autoras a partir do censo escolar da educação básica, com base em microdados disponíveis no site do Inep e utilizando o software SPSS.

9 Dados levantados pelas autoras a partir do censo escolar da educação básica, com base em microdados disponíveis no site do Inep e utilizando o software SPSS.
} 
A área vem investindo em um trabalho que considera, de forma prioritária, o diálogo, tanto entre as professoras da educação especial quanto com todo o grupo de docentes (cerca de cem) e demais profissionais que constituem a instituição. A construção do diálogo proposto apresenta-se de forma prioritária no trabalho desenvolvido e encontra embasamento na perspectiva sistêmica anunciada nesta pesquisa. A partir dos estudos de Bateson (1986), compreendemos a importância do estabelecimento de relações e inter-relações no intuito de corroborar com a proposição de pistas, fazeres e práticas pedagógicas. Logo, por mais que exista uma divisão por equipes, as docentes da área costumam conversar sobre os casos que acompanham entre si, o que garante o acompanhamento compartilhado e processual das demandas como um todo.

Torna-se importante mencionar que o CAp/UFRGS não conta, ainda, com o espaço físico de uma sala de recursos multifuncional ${ }^{10} \mathrm{e}$ os atendimentos ocorrem em uma sala compartilhada com a área de teatro da instituição. Assim, os atendimentos que visam a utilizar a sala precisam ser pensados tendo em vista o horário de utilização do espaço compartilhado.

A área de educação especial organiza todo o trabalho a ser realizado a partir de um Plano de Atendimento Educacional Especializado (Plano de AEE), o qual leva em consideração a história do aluno, desde o início da escolarização até o momento atual (em constante construção). Oferecemos destaque para esse ponto: a necessidade de contarmos a história do aluno atendido, pois compreendemos que, dentro de uma perspectiva articulada ao pensamento sistêmico, somos todos constituídos em termos de histórias. Segundo Bateson (1986):

Eu venho, entretanto, com histórias - não somente um suprimento de histórias para entregar ao analista, mas histórias construídas no interior do meu ser. Os padrões e sequências da experiência da infância estão construídos dentro de mim. Meu pai fez assim; minha tia fez de tal maneira; e o que eles fizeram estava fora da minha pele. Seja, porém, o que for que aprendi, meu aprendizado aconteceu dentro de minha sequência experimental do que aqueles 'outros importantes' - minha tia, meu pai - fizeram. (BATESON, 1986, p. 23).

Dentro da mesma perspectiva, o plano é ainda alimentado pelas habilidades e principais preferências do estudante, pela proposição de objetivos para o semestre, pelos recursos e materiais a serem utilizados e pela metodologia de avaliação a ser adotada. É fundamental destacar o caráter flexível do plano, que se constitui de forma a poder ser revisitado e alterado a qualquer tempo, pensando na dinamicidade dos processos de construção do conhecimento.

Nesse sentido, a partir da concepção do atendimento educacional especializado para além da sala de recursos multifuncionais, a área da educação especial da instituição passou a constituir uma proposição de atendimento em sintonia com essa perspectiva. No projeto da área ${ }^{11}$, apresenta-se $\mathrm{o}$ atendimento educacional especializado da seguinte forma:

[...] a área de educação especial do Colégio de Aplicação da Universidade Federal do Rio Grande do Sul compreende que o AEE não se restringe à sala de recursos multifuncionais. Desta forma, organiza-se a partir de uma visão de atendimento educacional especializado ampliada, apostando no caráter pedagógico deste espaço, compreendendo a potência da sala de aula regular e da articulação entre docentes na qualificação deste atendimento. [...] compreende que o atendimento educacional especializado ocorre ainda nos espaços de: assessoria à professores, parcerias docentes, iniciativas formativas que impliquem a instituição,

\footnotetext{
10 No contexto brasileiro, as salas de recursos multifuncionais foram implementadas através do Programa de Implantação de Salas de Recursos Multifuncionais, instituído por meio da Portaria no 13, de 24 de abril de 2007. Principalmente entre os anos de 2008 e 2013, diversas escolas foram contempladas com os recursos previstos no programa, com o objetivo de ofertar espaço e recursos qualificados para o atendimento educacional especializado. (BRASIL, 2007).

11 o projeto referido tem como objetivo apresentar a organização e os eixos orientadores do trabalho desenvolvido pela área de educação especial do CAp/UFRGS. O projeto está em construção e em tramitação no contexto da escola.
} 
atendimentos no contraturno, acompanhamento em sala de aula regular, entre outros. (ÁREA DA EDUCAÇÃO ESPECIAL, 2018).

De acordo com o projeto de área, assume-se, então, a compreensão do atendimento "[...] em sua complexidade como um serviço de apoio que vai para além de um espaço específico". (ÁREA DA EDUCAÇÃO ESPECIAL, 2018). Diante disso, a área de educação especial é concebida a partir de cinco eixos de trabalho: 1) atendimento educacional especializado, no contraturno; 2) apoio pedagógico em sala de aula regular; 3 ) assessoria a professores; 4) bolsistas de acompanhamento de processos inclusivos; e 5) oficinas.

O eixo que refere o atendimento educacional especializado no contraturno estabelece, como o título indica, a uma proposição de atendimento nos moldes anunciados pelas normativas. Assim, propõe-se que o atendimento seja pensado a partir das necessidades específicas de cada aluno, de forma a organizá-lo individualmente ou em grupos, de acordo com a carga horária. Segundo o texto do projeto de área:

Não há uma pré-definição de como irá se constituir o atendimento, cada aluno e cada tempo escolar demanda um tipo de planejamento diverso o qual se estrutura a partir do Plano de AEE que é construído a partir da entrevista com a família, diálogo com os professores, perfil do estudante e demais especificidades. Ressalta-se que o fato da criança/adolescente/adulto ser público-alvo da educação especial, não implica necessariamente a frequência neste atendimento, cabendo aos professores da área, em consonância com a família e outros atendimentos, avaliarem cada situação individualmente. (ÁREA DA EDUCAÇÃO ESPECIAL, 2018).

O eixo acerca do apoio pedagógico em sala de aula refere-se a uma proposição que articula o acompanhamento do aluno em sala de aula regular em uma perspectiva de docência compartilhada junto ao professor da turma. Dessa forma, as combinações referentes ao planejamento e desenvolvimento da aula ocorrem de forma dialogada e têm como objetivo qualificar a relação do aluno público-alvo com a turma. Acreditamos na potência desse eixo, pois identificamos a necessidade de um trabalho construído de modo contextual, o qual tende a corroborar com a perspectiva inclusiva. Quando articulamos o trabalho desenvolvido no atendimento educacional especializado com a construção pedagógica coletiva do contexto escolar, desenvolvemos, a partir de uma abordagem sistêmica, a compreensão de que sistemas são totalidades integradas, cujas propriedades não podem ser reduzidas a unidades menores. Todo organismo é uma totalidade integrada (CAPRA, 2002). A partir dessa premissa, existiria uma impossibilidade de realizarmos um trabalho quase que unilateral entre o professor da área de educação especial e seu alunado.

Ainda, a partir dessa compreensão, a assessoria a professores diz respeito ao espaço de diálogo ofertado para os professores de sala de aula regular, com o objetivo prioritário de discutir questões mais pontuais acerca de proposição/adequação de atividades, avaliação, planejamentos e casos específicos envolvendo os alunos atendidos. Cabe destacar que o movimento de discussão acerca dos alunos ocorre, ainda, no grande grupo de professores, durante as reuniões de equipe, espaço que consideramos fundamental nesse sentido. No entanto, tal espaço, em diversos momentos, fica subutilizado, dadas as intensas demandas emergentes que são colocadas para as equipes.

O eixo referente aos bolsistas de acompanhamento de processos inclusivos trata do trabalho organizado em diálogo com os nossos bolsistas de apoio para o atendimento e acompanhamento dos alunos público-alvo. A área conta com cinco bolsas ${ }^{12}$ ligadas aos processos inclusivos e os bolsistas são orientados, regularmente, para atuarem nas turmas em que se inserem, buscando desconstruir a ideia de um para um, ressignificando a atuação para além do acompanhamento

12 As bolsas de acompanhamento dos processos inclusivos estão vinculadas à Pró-Reitoria de Assuntos Estudantis da UFRGS. Para mais informações, acessar o site: https://www.ufrgs.br/prae/bolsas/. 
de um aluno específico. Os bolsistas são estudantes dos cursos de licenciatura da universidade e, portanto, a área também assume um compromisso formativo com relação à profissão docente, uma vez que estudantes/futuros professores também podem, por meio dessa experiência, qualificar os entendimentos sobre os processos de escolarização e os aspectos relacionados à perspectiva inclusiva. Destacamos a potência formativa deste espaço, tendo em vista que estes futuros professores têm a possibilidade de viver a docência, no âmbito do cotidiano escolar, em um processo dinâmico e que se constitui a partir da experiência. Bateson (1994) afirma que todos sabemos (ou deveríamos) da impossibilidade de aprendermos a dançar apenas lendo um livro. Para que se aprenda a dançar, torna-se necessário que se dance e que se viva o espaço de construção de conhecimento que apenas a experiência permite construir. Diante disso, pautadas nas palavras do autor, salientamos a impossibilidade de aprender a ser professor apenas a partir de leituras e estudos teóricos. Enfatizamos, assim, a importância de espaços que permitam a articulação entre teoria e prática e consideramos, a partir das análises, que o espaço de trabalho ofertado aos bolsistas se constitui dessa forma, na medida em que permite aliar a prática (experiência vivida na escola) e a teoria (estudos desenvolvidos nos cursos de graduação).

Por fim, as oficinas referem-se à entrada das professoras de educação especial em atividades desenvolvidas pelos projetos de ensino. Logo, as docentes inserem-se nas oficinas oferecidas no âmbito dos anos iniciais, nas disciplinas de iniciação científica, entre outros elementos ofertados, de acordo com os projetos de cada uma das equipes.

A área trabalha a partir de uma perspectiva pedagógica do processo de identificação. Portanto, os alunos são indicados pelos professores de sala de aula regular, geralmente em reuniões de equipe, e encaminhados para que a área de educação especial constitua esse processo. Para além da observação do aluno em sala de aula e da retomada de materiais e registros acerca do percurso de escolarização do aluno, as professoras de educação especial trabalham a partir de uma perspectiva dialógica com professores, profissionais técnicos do NOPE da escola, alunos, familiares/ responsáveis e demais profissionais que possam vir a atender o estudante.

A partir dessa construção, as professoras da educação especial constituem um parecer pedagógico que encaminha o aluno para o atendimento educacional especializado. Cabe destacar que esse movimento não desconsidera a importância do diagnóstico clínico em determinados casos, no entanto, para o acesso ao atendimento educacional especializado, não há a obrigatoriedade deste, tendo em vista o caráter pedagógico do atendimento. Diante disso, a área corrobora a compreensão estabelecida na Nota Técnica no 4/2014, que afirma:

[...] não se pode considerar imprescindível a apresentação de laudo médico (diagnóstico clínico) por parte do aluno com deficiência, transtornos globais do desenvolvimento ou altas habilidades/superdotação, uma vez que o AEE caracteriza-se por atendimento pedagógico e não clínico. Durante o estudo de caso, primeira etapa da elaboração do Plano de AEE, se for necessário, o professor do AEE, poderá articular-se com profissionais da área da saúde, tornando-se o laudo médico, neste caso, um documento anexo ao Plano de AEE. Por isso, não se trata de documento obrigatório, mas, complementar, quando a escola julgar necessário. $\mathrm{O}$ importante é que o direito das pessoas com deficiência à educação não poderá ser cerceado pela exigência de laudo médico. A exigência de diagnóstico clínico dos estudantes com deficiência, transtornos globais do desenvolvimento, altas habilidades/superdotação, para declará-lo, no Censo Escolar, público alvo da educação especial e, por conseguinte, garantir-lhes o atendimento de suas especificidades educacionais, denotaria imposição de barreiras ao seu acesso aos sistemas de ensino, configurando-se em discriminação e cerceamento de direito. (BRASIL, 2014, p. 3).

Silva (2016) ressalta que a Nota Técnica no 4/2014 é representativa de avanço em relação aos processos de identificação dos alunos público-alvo da educação especial no Brasil ao garantir 
a quebra de uma antiga dependência da área pedagógica para com a área clínica, assegurando a não exclusividade da avaliação clínica que, historicamente, tem utilizado, no caso de alunos com deficiência, uma lógica predominante psicométrica e pouco valorizadora de uma abordagem contextual. Como diria Vasconcellos (2002, p. 112), fazendo a inversão da ótica utilizada, estaríamos tirando o foco exclusivo no sujeito e incluindo o foco nas relações que se estabelecem em seu contexto.

Além das questões expostas, as professoras responsáveis pela área organizam, ainda, um parecer avaliativo a cada semestre, a ser compartilhado com as famílias. Esse parecer considera, de forma prioritária, o processo de construção de conhecimento do estudante e tem como objetivo dar legitimidade a esse percurso, tomando como base os objetivos traçados no Plano de AEE e destacando os avanços percebidos ao longo do semestre. Considera-se a importância da construção de um percurso, que esse seja destacado a partir do parecer, comunicando os passos que constituíram a caminhada, ou seja, em que pontos o estudante avançou. Destacamos a riqueza do processo, pois residem no percurso, no caminhar, as pistas acerca daquilo que se construiu.

\title{
Considerações finais
}

Pretendeu-se, a partir da escrita do presente texto, evidenciar a constituição de políticas e práticas que se articulem ao atendimento educacional especializado no contexto específico do CAp/ UFRGS. A partir da pergunta norteadora, problematizamos de que forma vem se desenhando a estrutura do atendimento educacional especializado no âmbito do Colégio de Aplicação.

Com base no exposto, procuramos sinalizar o trabalho que vem sendo desenvolvido no contexto analisado, o qual está pautado em uma proposição que valoriza o trabalho construído em rede. Nesse sentido, compreendemos que, para um processo inclusivo de qualidade, é necessário disponibilidade, participação ativa e tomada de responsabilidade de todos os integrantes da comunidade escolar. Di Pasquale e Maselli (2014, p. 714) apontam que:

\begin{abstract}
A inclusão de qualidade está ligada, portanto, ao crescimento de uma qualificação de competências tanto em termos de estrutura quanto do exercício da responsabilidade pessoal; não é um aspecto particular, mas um desafio coletivo que põe em questão todo o sistema escolar em sua capacidade de atender às exigências e necessidades de formação dos indivíduos dentro de uma estrutura de governança de políticas.
\end{abstract}

As palavras das autoras abordam um ponto nevrálgico relacionado às atuais práticas inclusivas no contexto escolar. Entendemos que o atendimento educacional especializado, seu espaço físico de articulação prioritário, a sala de recursos multifuncional e os profissionais especializados são partes representativas e importantes das atuais práticas educacionais, porém não são suficientes para abarcar o que se compreende por educação inclusiva.

Convém destacar que o processo de escolarização, fundamentado nessa perspectiva, necessita ser ressignificado com vistas a desenvolver um atendimento educacional especializado balizado pelas necessidades apontadas pelos estudantes (nas pistas que são indicadas por eles) e não voltado somente às ações realizadas na sala de recursos, por exemplo. A centralidade desse entendimento situa-se na busca de construir uma oferta que almeje concretizar os processos inclusivos dos estudantes de forma efetiva. Portanto, acredita-se na constituição de um trabalho em rede, pautado no entendimento de que o profissional especializado não deve ser considerado e tampouco agir como o único responsável pelas ações inclusivas, ocasionando, assim, uma delegação de responsabilidade, como se o processo inclusivo fosse passível de ser conduzido por um agente isolado. 
Diante disso, acreditando na potência de um trabalho articulado a partir das relações e do diálogo, ressignificamos a compreensão do atendimento educacional especializado, compreendendo que este deva se articular aos demais âmbitos do contexto escolar e não apenas aos espaços da sala de recursos, do atendimento individualizado, etc.

Utilizamos o conceito de rede para sinalizar que, ao falarmos de um sujeito, falamos de muitos outros presentes nas relações que são a história manifesta nessa pessoa. Assim, necessitamos conhecer o contexto em que esse sujeito se insere. Ao falarmos sobre nossos alunos, é importante termos a clareza de que não estamos falando apenas do seu corpo, de sua mente, da escola, da família, do sistema e de todas as demais redes que constituem essa(s) teia(s), de forma segregada e simplificadora. Estamos falando de todas essas instituições que os constituem de forma complexa e não linear.

É nesse sentido, como já sinalizado anteriormente, que nos pautamos na construção de um Plano de Atendimento Educacional Especializado, pensado a partir das necessidades e potencialidades específicas de cada aluno. Ao assumirmos uma observação contextual e menos simplificadora sobre nossos alunos, tendemos a reconhecer com maior facilidade as relações e interações que se estabelecem durante os processos de escolarização desses estudantes e, então, pensar e planejar, como rede, estratégias específicas de atendimento.

Diante da análise, compreendemos que o trabalho do atendimento educacional especializado constituído no contexto do CAp/UFRGS se pauta, de forma prioritária, pelo conceito de complexidade. A complexidade, nesse sentido, assume o sentido de "construído junto", "costurado" de forma articulada, ou seja, trata-se de um trabalho que se organiza considerando as redes de relações que se constituem naquele contexto como orientadoras do percurso. (VASCONCELLOS, 2012, p. 110).

Torna-se fundamental destacar, ainda, que o contexto em questão, o CAp/UFRGS, é uma instituição viva, dinâmica e em constante processo de transformação, como toda escola deve ser. Diante disso, o contexto também está em processo de construção de conhecimento acerca desses processos que colocamos em voga. $\mathrm{O}$ aprender, portanto, envolve necessariamente a ideia apresentada por Maturana e Varela (2001), quando afirmam que todo o processo de conhecer envolve um fazer, ou seja, não aprendemos de forma passiva, mas sim a partir da interação. Corroboramos aquilo que é apontado pelos autores ao afirmarmos que a instituição vem se constituindo/produzindo nessa rede em um movimento de retroalimentação, compondo, assim, uma das partes do sistema aprendente, que envolve, além da escola, os professores, os funcionários, os estudantes, as famílias, entre outros elementos.

Ao valorizarmos a importância de um processo de escolarização pensado a partir das relações entre seus partícipes, compreendemos que o trabalho pedagógico se articula a partir de uma ótica alinhada à perspectiva inclusiva. Segundo Maturana (1992, p. 244), aprender relaciona-se com nossas interações, pois, para o autor, “[...] aprender é conviver, quer dizer, o aprender se dá de uma maneira ou de outra na transformação que tem lugar na convivência, e consiste em viver o mundo que surge com o outro". Logo, cada vez que um dos elementos deste sistema aprendente se altera, todos os outros elementos sofrem uma alteração, em um processo de transformação contínua e compartilhada, tendo em vista sua dinamicidade. É acreditando nessa transformação que ocorre, a partir da relação com o outro, o trabalho do atendimento educacional especializado, desenvolvido no âmbito analisado, que vem se constituindo na defesa de uma construção pautada pelo coletivo, de forma dialógica e contextual. 


\section{Referências}

ÁREA DA EDUCAÇÃO ESPECIAL. Colégio de Aplicação. Projeto de Área da Educação Especial, 2018. p. 16.

BATESON, Gregory. Mente e natureza. Rio de Janeiro: Francisco Alves, 1986.

BATESON, Gregory; BATESON, Mary Catherine. El temor de los angeles. 2. ed. Barcelona: Gedisa, 1994. p. 218.

BAPTISTA, Claudio Roberto. Ação pedagógica e Educação Especial: a sala de recursos como prioridade na oferta de serviços especializados. Revista Brasileira de Educação Especial, v. 17, p. 59-76, 2011.

BRASIL. Resolução CNE/CEB n 2, de 11 de setembro de 2001. Institui Diretrizes Nacionais para a Educação Especial na Educação Básica. Brasília, DF: MEC/SEESP, 2001.

BRASIL. Ministério da Educação. Portaria normativa no 13, de 24 de abril de 2007. Dispõe sobre a criação do "Programa de Implantação de Salas de Recursos Multifuncionais”. Brasília, DF: MEC, 2007.

BRASIL. Ministério da Educação. Política Nacional de Educação Especial na perspectiva da Educação Inclusiva. Brasília, DF: MEC/SEESP, 2008.

BRASIL. Ministério da Educação. Resolução CNE/CEB No 4, de 2 de outubro de 2009. Institui Diretrizes Operacionais para o Atendimento Educacional Especializado na Educação Básica, modalidade Educação Especial. Brasília, DF: MEC/SEESP, 2009.

BRASIL. Decreto $N^{o} 7611$, de 17 de novembro de 2011. Dispõe sobre a educação especial, o atendimento educacional especializado e dá outras providências. Presidência da República. Brasília: MEC, 2011.

BRASIL. Ministério da Educação. Nota Técnica No 4, de 23 de janeiro de 2014. Orientação quanto a documentos comprobatórios de alunos com deficiência, transtornos globais do desenvolvimento e altas habilidades/superdotação no Censo Escolar. Brasília, DF: MEC, 2014.

BRASIL. Lei No 13.146, de 6 de julho de 2015. Institui a Lei Brasileira de Inclusão da Pessoa com Deficiência (Estatuto da Pessoa com Deficiência). Diário Oficial da União, Brasília, DF - Seção 1, p. 2, 7 de julho de 2015.

CAPRA, Fritjof. O ponto de mutação: a ciência, a sociedade e a cultura emergente. 23. ed. São Paulo: Cultrix, 2002.

DI PASQUALE, Giovanna; MASELLI, Marina. Pessoas com deficiência e escola: principais mudanças na experiência italiana. Revista Educação \& Realidade, Porto Alegre, v. 39, n. 3, p. 707-724, jul./set. 2014.

MATURANA, Humberto. El sentido de lo humano. 2. ed. Santiago: Hachette, 1992. p. 315.

MATURANA, Humberto; VARELA, Francisco. A árvore do conhecimento: as bases biológicas da compreensão humana. São Paulo: Palas Athena, 2001.

MENDES Jr, Edson; TOSTA, Estela Inês. 50 anos de políticas de educação especial no Brasil: movimentos, avanços e retrocessos. Anped Sul, Caxias do Sul, 2012.

PASSOS, Eduardo; KASTRUP, Virginia. Cartografar é traçar um plano comum. Fractal, Rev. Psicol., v. 25, n. 2, p. 263-280, maio/ago. 2013.

SILVA, Carla Maciel da. Deficiência intelectual no Brasil: uma análise relativa a um conceito e aos processos de escolarização. 2016. 102 f. Dissertação (Mestrado em Educação) - Programa de Pós-Graduação em Educação, Faculdade de Educação, Universidade Federal do Rio Grande do Sul, Porto Alegre, 2016.

VASCONCELLOS, Maria José Esteves de. Pensamento sistêmico: o novo paradigma da ciência. Campinas: Papirus, 2013. [ISBN 9788530806811].

WISCH, Tásia Fernanda. Contextos emergentes no Colégio de Aplicação: tessituras das docências na perspectiva inclusiva. 2020. 272 f. Tese (Doutorado em Educação) - Programa de Pós-Graduação em Educação, Centro de Educação, Universidade Federal de Santa Maria, Santa Maria, 2020.

Data de submissão: 14/05/2021

Data de aceite: $23 / 06 / 2021$ 